\title{
The employee's productivity in the health care sector in Poland and their impact on the treatment process of patients undergoing elective laparoscopic cholecystectomy
}

Patient Preference and Adherence

5 December 2016

Number of times this article has been viewed

\section{Anna Rosiek, ${ }^{1,2}$ Aleksandra \\ Rosiek-Kryszewska, ${ }^{3}$ Łukasz Leksowski, ${ }^{4}$ Tomasz Kornatowski, ${ }^{2}$ Krzysztof Leksowski ${ }^{2,5}$}

'Ross-Medica, ${ }^{2}$ Faculty of Health Sciences, Public Health Department, Nicolaus Copernicus University, ${ }^{3}$ Faculty of Pharmacy, Department of Inorganic and Analytical Chemistry, Nicolaus Copernicus University, ${ }^{4}$ Faculty of Health Sciences, Department of Rehabilitation, Nicolaus Copernicus University, ${ }^{5}$ Department of General Thoracic and Vascular Surgery, Military Clinical Hospital in Bydgoszcz, Bydgoszcz, Poland

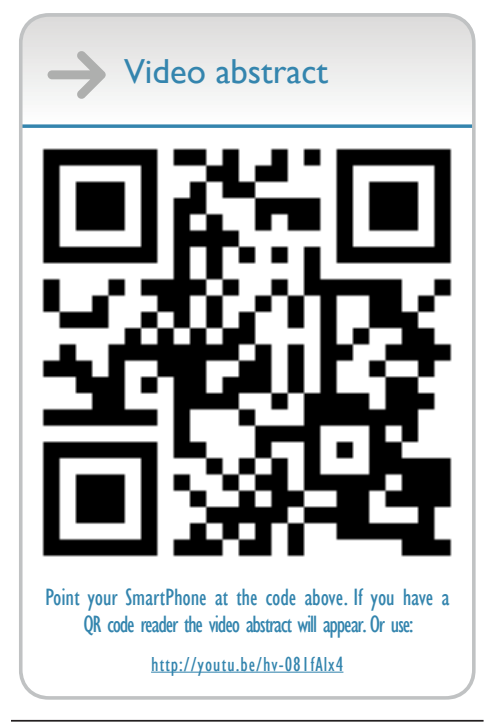

Correspondence: Anna Rosiek Faculty of Health Sciences, Public Health Department, Nicolaus Copernicus University in Toruń, Przodowników Pracy 8/7, 85-843 Bydgoszcz, Poland

Tel +48 668327327

Email ania.rosiek@wp.pl
Background: Increasing the engagement of employees in the treatment process of patients may benefit a hospital and employee productivity and may result in better patient care and satisfaction with medical services. Given this, the first step in improving the quality of patient care is better availability of doctors for patients in a hospital ward.

Methods: The research for this paper was conducted in six health care units in the KuyavianPomeranian province in Poland. The research assessed how the elements relating to employees' behavior and things characteristic to medical service influence patients' willingness to recommend a hospital.

Results: Patients' perception of services is linked with the behavior of medical employees and their engagement in the treatment process.

Conclusion: Our research indicates that individual employee recognition and collective recognition of hospital employees as a whole were identified as the most important factors in employee engagement in the treatment process (employee productivity) and patients' satisfaction with medical service.

Keywords: employee's productivity, workplace interventions to enhance health, hospitals, organizational health, medical staff, public health

\section{Introduction}

Customer satisfaction related to service-based industries is strongly influenced by the employees. As Poland and other advanced economies continue to shift from manufacturing to information and service-based industries, employees are taking an increasing role in driving organizational performance. One of the most important ways that employee's performance is affected is based on their interactions with customers. Accordingly, it is vital that companies understand concepts such as employee engagement and satisfaction and how these concept levels relate to customer satisfaction and overall customer experience. ${ }^{1}$

The medical market is dependent on the same laws. Patients want to be customers who can decide when and by whom they will be treated. Hospitals around the world should favor this new dynamic health care system as a means to save money and increase efficiency, ${ }^{2}$ which could change how the health care in Poland and around the world is perceived. The health care organizations are encouraged to form an accountable care organization - a concept designed to overhaul the nation's health care system by implementing structures that monitor the quality and efficiency of entire groups of 
medical practitioners in an effort to assess performance and create standards in hospital practices. ${ }^{2}$ Berwick has argued that this Hospital Value-Based Purchasing Program is another step toward shifting the reimbursement infrastructure from the cost of services to improvements in patients' health and general health care performance. In many public-financed health care systems, market-oriented health care reforms are being implemented. The purpose of these reforms is to make resource allocation in health care more efficient, more innovative, and more responsive to consumers' preferences while maintaining equity., ${ }^{2,3}$ At the same time, a divergence of consumers' preferences with respect to health care can be observed. From an international and Polish perspective, we can observe a trend toward universal mandatory health insurance, contracts between third-party purchasers (National Health Fund in Poland) and the providers of care (hospital), and competition among providers of care. Because the effectiveness of care in Poland has to be considered in relation to the condition of the patient and the course of treatment, the responsibility for cost-effective care rests primarily with the providers of care. ${ }^{3}$ The quality of health care is difficult for consumers and payers to judge, making it easy for care providers to compete looking only at cost of the expense of quality and equity in hospital services. Because of this, the quality of patient's care has been greatly discussed by the Polish Ministry of Health and the Quality Monitoring Center. By applying tools measuring and regarding quality in health sector, such as the law on quality of health care in Poland, and market-based measures to Polish health care, the system has effectively been changed and noneffective parts in health care organizations have been eliminated. This was a very important point for cost efficiency and quality of care in the Polish health system, especially because in many cases patients do not know the costs of the treatment and hospital services. Treatment for employed and insured National Health Fund patients in public hospitals is free and financed completely by the Polish National Health Fund.

A free medical health service and competitive medical market would likely have the approval of patients such as universal access to health care and waiting list times can be longer than what patients' expect. ${ }^{3}$ Micromanagement of interactions between patients and care providers does not guarantee quality care and frequently undermines that relationship to the frustration of all involved. ${ }^{3}$

There is an increase in the role of employees in creating a strong relationship with the medical organizations and patients receiving medical care. The changes that are observed in health care organizations are significant because they are focused on how to deliver higher quality care. Although some improvements in care quality can be reached through investments in technology and infrastructure, the most improvements could be achieved through investing in employees.

In the Polish health care system, improvements achieved through the employees could be difficult. The reform in the public health care sector in Poland, which was especially visible in the range of reduction of employees (surgeons and nurses) in public hospitals, was the basis for this research. The decrease in the number of employees, rising expectations of patients, and aiming for high-quality medical services require the manager to monitor patient's satisfaction and also organizational changes. Although research on patient's satisfaction with hospital treatment has been carried out in Poland, it has never taken into account the number of employees. There is a significant impact on the involvement of surgeons and nurses in the process of treatment on overall patient satisfaction.

Some previous studies have concluded that unsatisfied health care employees negatively affect the quality of care of patients, which adversely affects patient satisfaction and loyalty to a hospital. ${ }^{4,5}$ One would expect that increasing the engagement of employees may benefit a health care organization and result in improved patient care and higher patient satisfaction from medical services.

In the health care sector, greater employee engagement in planning, commissioning, and developing services is crucial in ensuring the high quality of medical service. ${ }^{6-8}$ Enhanced employee engagement is thought to lead to more benefits for patients, better health care outcomes, and more cost efficient for hospitals. ${ }^{8-11}$ There were several studies defining care provider engagement, ${ }^{12,13}$ one of which notes that "engagement is understood as the extent to which people perform their own work role and is related to their emotional experiences." 8 Although emotions and the role of medical employees (nurses etc) are important, in the integrated health care context, securing engagement is even more complex because of the challenges inherent in collaborative working (collaboration between doctors, nurses) across professional boundaries and different organizations and patient's expectations of medical services. ${ }^{8}$ The balance between these components is a guarantee of organizational success.

In our study, we have tried to demonstrate that the involvement of employee's in the process of the patient's treatment may impact the quality of service, patient satisfaction, and can benefit the organization. Before exploring some examples of medical engagement in practice, it is worth considering a number of earlier definitions. 
Guthrie $^{14}$ and also Erlandson and Ludeman ${ }^{15}$ argue that physician's engagement is one of the key priorities for health care managers and is one of the markers of better performing hospitals and quality of hospital service. MacLeod and Clarke ${ }^{11}$ provide an excellent account of employee engagement in the UK and across a range of sectors. Institute for health care Improvement in the USA developed a framework for how organizations might adapt to improve levels of physician engagement in quality and safety of patients in hospitals. This framework has six key phases:

1. discovering common purpose;

2. reframing values and beliefs;

3. segmenting the engagement plan;

4. using "engaging" improvement methods;

5. showing courage;

6. adopting an engaging style, for example, involving doctors in a way patients can see and valuing the doctor's time. ${ }^{16-18}$ This model of engagement with the presented framework has been used very successfully in a number of US hospitals and has been the basis for much of the Institute for health care Improvement's work with the National Health Systems. While some of the activities in the framework may be more relevant to the US - such as the phases of discovering common purpose, segmenting the engagement plan, and showing courage - the general approach is capable of adaptation to any health system. ${ }^{19}$

As we can see, the term "engagement" has acquired a range of meanings, but no universal definition exists in health care. We recognize, however, that engagement is a two-way process involving organizations working to engage employees and the patients' satisfaction with the doctors' (medical employees) work ${ }^{19}$; that engagement also correlates with performance and innovation of medical services. In order to better illustrate the process, Table 1 presents what benefits come from employees' engagement in the process of treating a patient.

For the purposes of this study, the authors take the definition of physician's engagement based on the definition by Spurgeon et al. ${ }^{20}$ Physicians are considered to be engaged when they display all three of the following engagement behaviors in organization:

1. consistently and clearly inform the patients about things such as how drug therapy works' possible side effects of drug therapy, etc;

2. intend to stay and continue practice (availability for patients);

3. strive to achieve above and beyond what is expected in their daily role (patient satisfaction and the recommendation of hospital's medical services).
Table I Benefits (for patients and organization) attributed to high level of engagement of employees in the treatment process

\begin{tabular}{|c|c|c|}
\hline & $\begin{array}{l}\text { Benefits attributed to high } \\
\text { level of engagement }\end{array}$ & $\begin{array}{l}\text { Disengagement } \\
\text { of employees }\end{array}$ \\
\hline Patients & $\begin{array}{l}\text { Patients' satisfaction } \\
\text { Better patients outcome } \\
\text { Higher quality of services and } \\
\text { willingness to recommend the } \\
\text { hospital } \\
\text { Patients' loyalty }\end{array}$ & $\begin{array}{l}\text { Patients' dissatisfaction } \\
\text { Patients are likely to } \\
\text { complain about the } \\
\text { behavior of disengaged } \\
\text { employees to their family } \\
\text { and friends } \\
\text { Unlikely to recommend } \\
\text { the hospital } \\
\text { Will seek alternative } \\
\text { health care units }\end{array}$ \\
\hline Organization & $\begin{array}{l}\text { Improved organizational } \\
\text { performance } \\
\text { Staff retention } \\
\text { Innovation of medical services }\end{array}$ & $\begin{array}{l}\text { No value to the } \\
\text { organization }\end{array}$ \\
\hline
\end{tabular}

Note: Data from The King's Fund. ${ }^{19}$

The engagement of professionals as defined earlier has a strong impact on the quality of medical services, employee productivity, and because of that the authors decided to assess the involvement of medical personnel in terms of how to improve medical services.

The aims of the study were to assess the engagement of medical employees in the treatment process on surgery wards in Poland and whether the level of employee engagement in the treatment process influences quality of care, patient's satisfaction, and patient's loyalty. This aspect also has never been studied in Polish hospitals, and this study addresses the gaps in the literature.

\section{Materials and methods Study design}

The authors of this paper undertook a process of evaluating employee's productivity in health care, which provided an overall framework for the study. The study is presented in three phases.

In phase I - literature was reviewed to identify theories concerning how health care employee's involvement can influence the quality of care, patient's satisfaction, and its impacts on the outcome of the treatment. Such theories are to be found in many publications, which review medical literature and professional journals. Enhanced employee engagement is thought to lead to more benefits for patients, better health care outcomes, and value for the hospital. Authors revised different definitions of physician's engagement in literature and for the purposes of this study, the authors have used the definition based on the one used in 
the study by Spurgeon et al. ${ }^{20}$ Such theories can be found in documentation containing guidelines (eg, Report from The King's Fund Commission on Leadership and Management in the NHS. London: The King's Fund). ${ }^{19}$

In phase II - the authors used the qualitative method (Servqual method) and the quantitative method (data from the human resources [HR] hospital department) to provide the data for the research. Comparison of the qualitative data obtained in the study and quantitative data from the HR department helped to draw general conclusions about the benefits of employee involvement in the process of treating a patient.

Authors decided to use the Servqual method to evaluate the quality of medical services carried out in health care from the perspective of external customer (patient) and the internal customer (employee). Among the variety of methods described in the literature that are used for measuring the quality of services in a specific environment of medical institutions is the Servqual method. The method was developed by Paraserman et $\mathrm{al}^{21-24}$ in the years 1983-1985 and consists of measuring the level of satisfaction, which is the difference between patient's expectations and perceptions (the actual state) of medical services by patient. ${ }^{25}$ The originality of this method lies in showing that the perceived quality of service is the result of comparison of service expected by the patient with the service received. Thanks to this method, one can measure the differences that exist between the quality perceived by a patient and service expected by said patient. In other words, this method tests patient's expectations regarding the service level and the actual level of service delivered by employees in a given hospital. It can also test the steps undertaken to improve the quality of health care service and their implementation, in particular medical facility by comparing patient's expectations and patient's perceptions of the service provided by this medical facility. The difference between the values desired by a patient in particular areas and the value perceived by said patient indicates the place where the organization should improve and also show which factors of employee's behavior are the most important in building customer loyalty.

The authors also decided to check whether there is a relationship between the number of employed medical employees and their commitment assessed by the patient. For this purpose, hard data were acquired from the HR department on the actual number of employees (doctors and nurses) on the analyzed wards.

Comparison of the data obtained in the study and data from the HR department helped to draw general conclusions about the benefits of employee involvement in the process of treating a patient for organizations.
In phase III - evaluation - a mixture of qualitative and quantitative methods is important to gather data on the mechanisms and contexts of employees' engagement and its impact on the treatment process of patients undergoing elective laparoscopic cholecystectomy. Data were collected using a range of methods, which are flexible enough to allow exploration with Servqual and HR data configurations. However, the data collection protocol was revised and further specified at the end of phase I in regard to the theories presented in literature. Comparison of Servqual with hard date from the HR department (number of employees and number of beds) is also researched. Servqual evaluation method is increasingly popular in assessing the implementation of quality of care and complex surgery interventions in health care $^{23}$ and has been applied in a variety of fields within health systems research, ${ }^{26,27}$ but has never been compared with the quantitative data, especially with the number of employees in a hospital ward.

\section{Population}

The research for this paper was conducted in six health care units in the Kuyavian-Pomeranian province in Poland. All the hospitals were located in one region (the area of one province), and their services were financed by a single and the same payer: they were financed from state funds (National Health Fund in Poland).

Authors divided the hospitals into groups below and above 400 beds, in accordance with guidelines of National Health Fund in Poland defining small ( $<400$ beds) and big $(>400$ beds) hospitals. The study included patients undergoing elective laparoscopic cholecystectomy, because it is one of the most commonly performed surgical procedures today. Authors decided to compare opinions of patients suffering from the same International Classification of Diseases-10 code (K80).

These patients often make up the highest number of patients treated in surgical departments and therefore, their opinion may have a significant impact on the image of the surgical ward, the quality of care, engagement of medical employees, and indirectly, the organization of hospital work.

\section{Instrument}

The Servqual instrument is a useful measurement tool in assessing and monitoring service quality in a surgery ward, enabling the employees to identify where service improvements are needed from the patients' perspective. Servqual represents service quality as the discrepancy between a customer's expectations for a service offered and the customer's perceptions of the service received. ${ }^{23}$ The original Servqual contains 22 paired items on a Likert scale of five service 
quality dimensions: tangibility (A, material area), reliability ( $\mathrm{B}$, reliability area), responsiveness $(\mathrm{C}$, reaction in response to patients' expectations), assurance ( $\mathrm{D}$, competence), and empathy (E, empathy). ${ }^{22-24}$ In the first part of the study, the respondents declared their expectations of service quality regarding these five items, and in the second part, the level of perceived performance ${ }^{28}$ provided by them.

The survey was done during the patients' hospital stay and on the third day after surgery. The questionnaire used in this study was the original Servqual method with a 5-point Likert scale from strongly disagree- 1 to strongly agree-5. To calculate overall quality of hospital services in all dimensions, the authors compared patient's view of health care and their expectation. Score value above zero indicates on patient satisfaction. ${ }^{28-30}$

To assess the involvement of employees in treatment process questions concerning the medical employees and relating their involvement in the process of patient treatment were selected (Does medical employees [doctors, nurses] explain to patients how a drug works and what can be its side effects? Are the doctors available for patients 24/7?). The authors then compared them with quantitative data on employment.

The research assessed how the elements relating to employee's behavior and characteristics of medical service influence patients' willingness to recommend a hospital. Apart from that, the researchers also took into account hospital personnel.

At the end of the questionnaire, the authors asked respondents about their background data such as sex, age, and place of living, which were then analyzed in detail.

The research data were collected from June to December 2011, and results were analyzed statistically in 2012. The software STATISTICA ${ }^{\circledR}$ Version 10.0 (Statfost Polska Sp zoo, Krakow, Poland) was used for statistical analysis throughout this research. The authors used statistical tests of Spearman and Mann-Whitney $U$-test.

\section{Analysis}

The units were divided into two groups depending on the number of hospital beds (group I $>400$ beds and group II $<400$ beds). The first group consisted of three hospitals with $>400$ beds (two University Hospitals and a Military Clinical Hospital with a total number of employees $>900$ ), and the second group consisted of three hospitals with $<400$ beds (Regional Hospitals with a total number of employees $<900$ ). Within each group, the hospital wards were similar in terms of the patients they treat (surgery wards).
The research included 180 patients in each group: 30 from each hospital's surgery ward. Patients were selected randomly from the group of patients undergoing elective laparoscopic cholecystectomy. Involvement of the patient in the study was voluntary and the patients' classification for the research was carried out on the surgery ward. Inclusion criteria to take part in the study were:

1. patient's agreement to be included in the study,

2. patients' undergoing elective laparoscopic cholecystectomy,

3. hospital stay was up to 3 days. The third day was the last day of patient's hospital stay.

\section{Ethics}

The Institutional BioMedical Ethics Committee approved this study. Written informed consent for participation in the study and for publication of this report was obtained from all participants.

\section{Results}

The largest group consisted of patients between the ages of 41 and 60 years. Most patients in group I were inhabitants of towns, while in group II, more patients were residents of rural areas. In both groups, the majority of patients were women (Table 2).

The result of this study indicates that the hospital wards with the number of beds below and above 400 should provide the service that would satisfy both subjective and objective factors influencing patient satisfaction. In both groups, patients assessed the explanation of drug therapy as an important factor influencing medical services provided by medical employees. This is a significant element in their assessment of medical service; the same goes as engagement

Table 2 Demographic data

\begin{tabular}{|c|c|c|c|c|c|c|c|}
\hline & \multicolumn{2}{|l|}{ Group I } & \multicolumn{2}{|l|}{ Group II } & \multicolumn{2}{|l|}{ Total } & \multirow[t]{2}{*}{$P$-value } \\
\hline & Number & $\%$ & Number & $\%$ & Number & $\%$ & \\
\hline Sex & & & & & & & $>0.05$ \\
\hline Women & 59 & 65.6 & 68 & 75.6 & 127 & 70.6 & \\
\hline Men & 31 & 34.4 & 22 & 24.4 & 53 & 29.4 & \\
\hline Sum & 90 & 100.0 & 90 & 100.0 & 180 & 100.0 & \\
\hline \multicolumn{3}{|c|}{ Place of living } & & & & & $<0.05$ \\
\hline Town & 71 & 78.9 & 43 & 47.8 & 114 & 63.3 & \\
\hline Rural area & 19 & 21.1 & 47 & 52.2 & 66 & 36.7 & \\
\hline Sum & 90 & 100.0 & 90 & 100.0 & 180 & 100.0 & \\
\hline Age & & & & & & & $>0.05$ \\
\hline$<40$ years & 19 & 21.1 & 14 & 15.6 & 33 & 18.3 & \\
\hline $4 I-60$ years & 42 & 46.7 & 47 & 52.2 & 89 & 49.5 & \\
\hline$<60$ years & 29 & 32.2 & 29 & 32.2 & 58 & 32.2 & \\
\hline Sum & 90 & 100.0 & 90 & 100.0 & 180 & 100.0 & \\
\hline
\end{tabular}




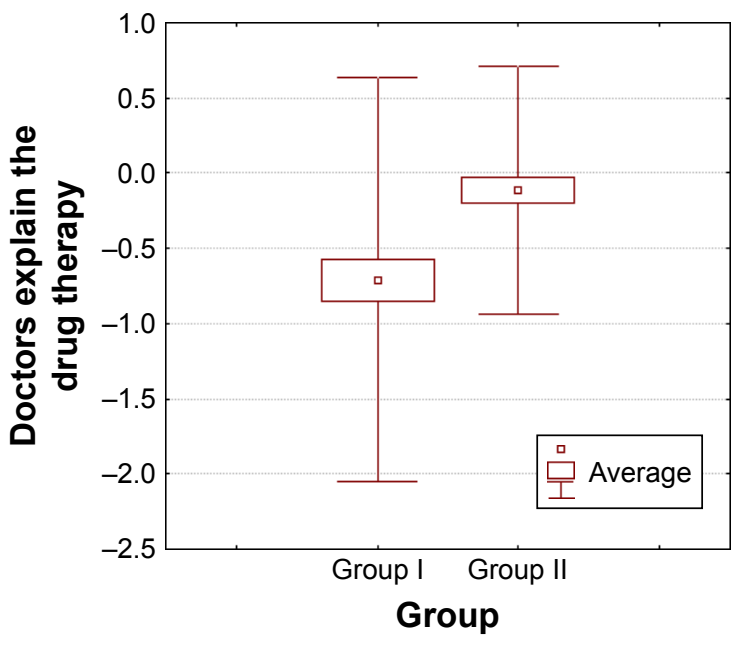

Figure I Explanation of how the drug therapy works and its possible side effects. Notes: Group I, hospitals with less than 400 beds; group 2, hospitals with more than 400 beds.

of the doctors in patient treatment $(P<0.05)$. The availability of doctors on the ward is also important for patients, and in the assessment of the services patients indicated it as a significant element of care $(P<0.05)$. Hospitals should pay specific attention to these factors in the interests of improving strictly clinical elements but also the level of medical services and the engagement of medical employees in the treatment process.

Mann-Whitney $U$-tests showed the explanation of how the drug therapy works and how its possible side effects can have an impact on patient assessment of medical services in hospital practices. Expectations of patients from groups I and II were not fulfilled $(P<0.05$; Figure 1 , Table 3$)$. The existing state was, however, assessed much better by patients from group II. Patients from group II also better assessed the availability of doctors on the ward (24 hours), so their perception of efficient realization of medical service was better in those aspects (Figure 2; Table 4). Patients' perception of services is linked with the behavior of medical employees and their engagement in the treatment process (Table 5). Patients as the person with the most at stake are able to assess the behavior and involvement of medical employees in the process of treatment, although patient's opinion may be subjective in this case. Patients' opinion and assessment of the quality of medical services should not be ignored because it significantly influences patient loyalty and their satisfaction with the service and following that, the real results of the treatment process.

Mann-Whitney $U$-tests showed that, for both groups, the availability of 24 hours of doctor care is a significant element influencing patient satisfaction and their loyalty $(P<0.05)$. The presence of a doctor in a hospital ward also improves the realization of medical service and similarly to the parameter describing the explanation of drug therapy to patients is more influential on the quality of medical care. Those parameters are also the answers for hospital managers in how deeply the doctors are engaged in the treatment process (Figure 3, Table 5). If the medical employees feel they are more engaged in the treatment process, the organizational culture is much higher. This factor, and its detailed analysis, shows that if a hospital wants to create a strong organizational culture and improve quality of care and thus reinforce patient satisfaction and loyalty, close cooperation with the HR department is necessary. Comparing these two elements, one can also see how they influence the eventual willingness of patients to recommend a hospital. This relationship is shown in Figure 4.

This study showed that patients from group I assessed the engagement of medical employees and their 24 hour availability for patients in the ward much better. The same patients (from hospitals with the number of beds $>400$ ) are more willing to recommend hospital services than the patients from the hospitals with the number of beds $<400$. This confirms that the engagement of medical employees in treatment processes and patient safety influence a large degree of patient's loyalty and his/her desire to recommend the hospital services.

The authors compare the result of this survey with the account of medical employees in each hospital group groups I and II.

Analysis of the number of medical employees employed in both groups of hospitals (Table 6) shows that there was a significant difference in the number of patients per one doctor in the ward. In hospitals of group I, there was an average of one doctor per 1.5 patients, while in hospitals of group II, there was an average of one doctor per 4.5 patients. In the case of nurses in hospitals of group I, there were 0.8 patients per one nurse, while in group II, there were 1.2

Table 3 Do medical employees explain to patients about the drug therapy and its side effects?

\begin{tabular}{lllllllll}
\hline $\begin{array}{l}\text { Sum.rang, } \\
\text { Group I }\end{array}$ & $\begin{array}{l}\text { Sum.rang, } \\
\text { Group II }\end{array}$ & $\mathbf{U}$ & $\boldsymbol{Z}$ & P-value & Z Corrected & P-value & $\begin{array}{l}\text { N ważn. } \\
\text { Group I }\end{array}$ & $\begin{array}{l}\text { N ważn. } \\
\text { Group II }\end{array}$ \\
\hline $7,194.5$ & $9,095.5$ & $3,099.5$ & -2.71932 & 0.00654 & -2.95539 & 0.00312 & 90 & 90 \\
\hline
\end{tabular}

Note: Group I $>400$ beds; group II $<400$ beds. 


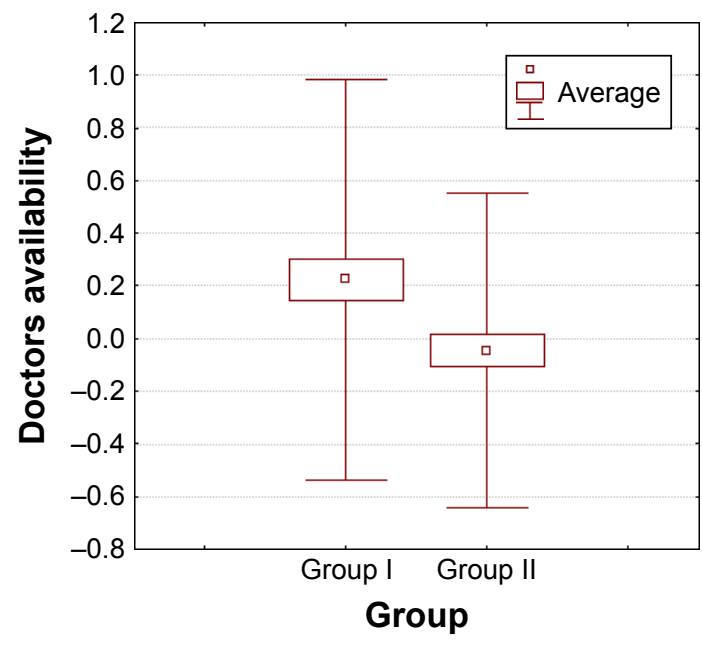

Figure 2 Availability of 24 hours of doctor care for patients on hospital ward. Notes: Group I, hospitals with less than 400 beds; group 2, hospitals with more than 400 beds.

patients per one nurse. In group I, there were 0.6 nurses and 0.3 doctors per bed, while in group II, there were 0.5 nurses and 0.2 doctors per bed.

The results of the study vary between groups I and II. Although in group II there is a smaller number of doctors on the surgery ward, patients assess that doctors from this group explain how the drug therapy works and its possible side effects better. Patients from group I assessed the engagement of medical employees and their 24 hour availability for patients in the ward much better. This confirmed that the amount of medical employees have an impact on patient's assessment of medical services in hospital.

Summary of the obtained results, in order to better illustrate the presented issues, is shown in Table 7.

Constant availability ( 24 hours) of doctor's care significantly influences patient's satisfaction and patient's loyalty. Through engagement of medical employees availability of 24 hours doctors in the ward, explaining to patients about the drug therapy by medical professional, and informing patients about possible side effects of drug therapy in the treatment process influences patient's loyalty and patient's willingness to recommend hospital services. The engagement of medical employees in the treatment process was higher in group I (patient's satisfaction, patient's loyalty, and willingness to recommend hospital services). Employment rate (number of employees) was also higher in group I than in group II.
A strong relationship exists between employee engagement and patients' perceptions of hospital services and the quality of care, measured in terms of patient's intent to return and also to recommend the hospital service to others. A lower level of employee engagement in the treatment process negatively influence the quality of care and have unfavorable effect on patient loyalty, and thus hospital profitability ratio in the long term decreased. Therefore, health care marketers should regularly measure employee engagement and patient's satisfaction as one way to monitor the service quality in hospital practices. HR departments and health care marketers should work more closely to understand what influences employees' work environment of medical employees and their high level of job satisfaction. Marketers should also place an increased emphasis on patient perceptions of satisfaction when developing hospital strategic marketing plans and formulating future research for an organization. It is important because it also helps to increase hospital net income.

\section{Discussion}

Satisfaction is a level to reflect customer confidence, a combination of emotion and decision..$^{31} \mathrm{~A}$ lot of research on marketing have shown that the utilitarian, hedonic value, and satisfaction are related. ${ }^{32-35}$ Customer satisfaction and the positive influence on loyalty have been widely supported by references related to marketing research. ${ }^{35,36}$ Satisfaction can be regarded as a key to establishing and maintaining loyalty and a foundation for customers to use a service for a long period of time. High satisfaction can enhance the possibility of recommending a service to other customers. ${ }^{36,37}$ Our study also confirms that satisfied patients recommend the hospital in which they stayed and the medical services provided by that hospital. Thus, customer satisfaction is the most important factor for enterprise operation and customer loyalty.

In many cases, new technology and technologically advanced procedures are not sufficient from patient's point of view.

Experiences from Polish and other European hospitals show that a hospital department with higher levels of employee engagement in the treatment provides better experience for patients, and by the same token, patient who

Table 4 Are the doctors available for patients on the ward for 24 hours?

\begin{tabular}{lllllllll}
\hline $\begin{array}{l}\text { Sum.rang, } \\
\text { Group I }\end{array}$ & $\begin{array}{l}\text { Sum.rang, } \\
\text { Group II }\end{array}$ & $\boldsymbol{U}$ & $\boldsymbol{Z}$ & $\boldsymbol{P}$-value & Z Corrected & Level P & $\begin{array}{l}\text { N ważn. } \\
\text { Group I }\end{array}$ & $\begin{array}{l}\text { N ważn. } \\
\text { Group II }\end{array}$ \\
\hline $8,927.0$ & $7,363.0$ & $3,268.0$ & 2.23726 & 0.02527 & 2.86344 & 0.00419 & 90 & 90 \\
\hline
\end{tabular}


Table 5 Patients' satisfaction with quality of care and their assessment

\begin{tabular}{|c|c|c|c|c|c|c|}
\hline \multirow{2}{*}{$\begin{array}{l}\text { Patients' satisfaction with quality of care and } \\
\text { their assessment }\end{array}$} & \multicolumn{2}{|l|}{ Group I } & \multicolumn{2}{|l|}{ Group II } & \multicolumn{2}{|l|}{ Total group } \\
\hline & Average value & SD & Average value & SD & Average value & SD \\
\hline Patients' satisfaction with quality of care & 0.28 & 0.71936 & 0.08 & 0.47941 & 0.18 & 0.61776 \\
\hline Willingness of patients to recommend a hospital & 0.08 & 0.81043 & -0.11 & 0.74116 & -0.02 & 0.78017 \\
\hline Empathy of medical employees & 0.22 & 0.84505 & 0.06 & 0.62461 & 0.14 & 0.74567 \\
\hline $\begin{array}{l}\text { Patients' assessment of doctor engagement in the } \\
\text { treatment process }\end{array}$ & 0.24 & 0.70808 & 0.02 & 0.63561 & 0.13 & 0.68012 \\
\hline Doctor's availability for patients on the ward $-24 / 7$ & 0.22 & 0.76110 & -0.04 & 0.59796 & 0.09 & 0.69547 \\
\hline
\end{tabular}

Notes: Group I, hospitals with less than 400 beds; group 2, hospitals with more than 400 beds.

Abbreviation: SD, standard deviation.

are more satisfied are more likely to recommend the hospital to others. The results of our study also confirm this fact. Our research also shows that elements such as explaining the drug therapy and also the availability of a doctor on the ward are highly influential on patient loyalty and better patient care. Ketter $^{38}$ reported that there exists evidence that personnel engagement has a positive correlation with individuals, groups, and also organizational performance in areas such as productivity, customer services, and loyalty, customer turnover, and retention. Our research also shows this tendency clearly.

Donabedian ${ }^{3}$ defined three components of quality: technical quality of care, interpersonal quality of care, and amenities. This research focuses on and discusses only interpersonal quality of care, which is reflected in patient's loyalty. This interpersonal quality of care describes the characteristics of interaction between care provider and patient. Although the association between physician's engagement and elements of interpersonal quality of care (such as patient satisfaction and loyalty ${ }^{39-41}$ ) has been described, the relationship between

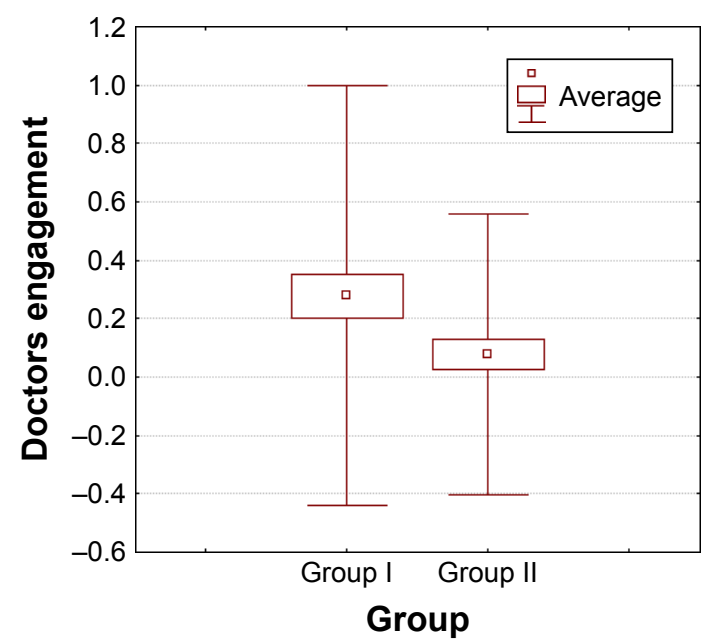

Figure 3 Patients' assessment of doctor engagement in the treatment process. Notes: Group I, hospitals with less than 400 beds; group 2, hospitals with more than 400 beds. physician's satisfaction and technical quality of care has not been established. Experiences from Japanese hospitals show that there was no association between physician's job satisfaction and the technical quality of care, ${ }^{42}$ although the impact on the involvement of medical personnel in the quality of medical services can be immediately ruled out.

Creation of the hospital's image, organizational culture which is determined by the behavior of medical employees and desire to maintain the positive image through high quality medical services (in the patient's opinion) is a process that requires constant improvement. The improvement in this area should be conducted on the basis of creating such a model that would lead to the improvement of patient's comfort of living, quality of medical services and, similarly, would lead to patient's positive opinion regarding functioning of a hospital. As a consequence, one will be able to observe the development of the positive employees engagement and organizational culture of a medical unit that would result from increased patient loyalty and satisfaction with his/her stay at a hospital.

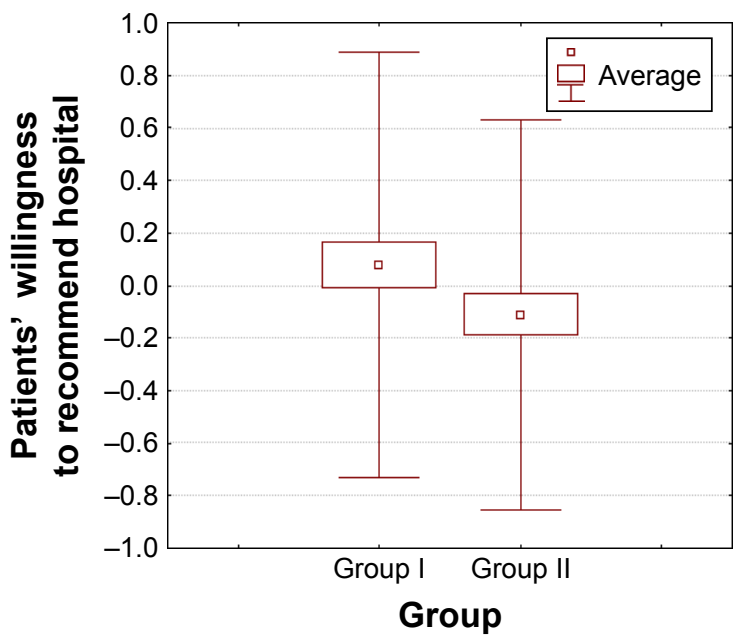

Figure 4 Patients' willingness to recommend hospital services.

Notes: Group I, hospitals with less than 400 beds; group 2, hospitals with more than 400 beds. 
Table 6 Analysis of the number of employed medical employees in groups of hospital

\begin{tabular}{|c|c|c|c|}
\hline No & Personnel & Group I & Group II \\
\hline I & The number of doctors on the ward & 33 & 17 \\
\hline 2 & The number of nurses on the ward & 61 & 49 \\
\hline 3 & $\begin{array}{l}\text { Number of patients hospitalized for } \\
\text { cholelithiasis in the period of research }\end{array}$ & 444 & 565 \\
\hline 4 & $\begin{array}{l}\text { The number of patients for one } \\
\text { doctor in the ward }\end{array}$ & 1.5 & 4.5 \\
\hline 5 & $\begin{array}{l}\text { The number of patients for one nurse } \\
\text { in the ward }\end{array}$ & 0.8 & 1.2 \\
\hline 6 & The number of nurses per bed & 0.6 & 0.5 \\
\hline 7 & The number of physicians per bed & 0.3 & 0.2 \\
\hline
\end{tabular}

Notes: Group I, hospitals with less than 400 beds; group 2, hospitals with more than 400 beds.

In the current model of how public health care units function in Poland, processes related to the improvement of a health care unit through high-quality medical service are underappreciated and sometimes disregarded altogether by hospital's managers. Seeing how the market works, it seems unwise. After all, hospitals - similarly to companies entered the market and are surrounded by increasing competition. As a consequence, they started to try to attract patients, their loyalty, satisfaction, and trust. Wanting to maintain its position on the market, a hospital should care to improve managing processes on all the levels of organization's functioning.

Patient's loyalty and satisfaction are key elements in measuring quality in medical units. Measuring of these elements is important in every branch of business because customers' satisfaction translates into his/her loyalty. Scientific studies $^{26-28,40,43}$ show that a patient who is satisfied are more likely to recommend the hospital he/she was visiting and return there if such a need occurs or when their life and health are in danger, and this fact is also shown by our research.

In health care, patient's satisfaction is very important. Satisfied patients usually are the group whose treatment administered by a medical unit ended successfully. ${ }^{44}$ Therefore, patient satisfaction with their treatment translates to both

Table 7 Engagement of medical employees in the treatment process on hospitals wards

\begin{tabular}{ll}
\hline $\begin{array}{l}\text { Engagement of medical employees in the treatment } \\
\text { process assessed by patients in groups I and II }\end{array}$ & $P$-value \\
\hline $\begin{array}{ll}\text { Availability of } 24 \text { hours doctors in the ward } \\
\text { Explaining patients about the drug therapy by medical }\end{array}$ & $<0.05$ \\
$\begin{array}{l}\text { professional } \\
\text { Informing patients about possible side effects of drug }\end{array}$ & $<0.05$ \\
therapy & $<0.05$ \\
\hline
\end{tabular}

Notes: Group I, hospitals with less than 400 beds; group 2, hospitals with more than 400 beds. patient's health and a smaller cost to health care. That is why it is so vital for a health care unit to strive to improve patient satisfaction with the treatment. It should be noted that in a situation where patients have the option of multiple choice, sometimes they will not recommend the medical unit they stayed at, even though they were satisfied with their stay. Sometimes it is due to the fact that patient's satisfaction was caused by their general health improvement. ${ }^{45}$ However, patient's willingness to recommend a health care unit and his/ her desire to return to the same unit are caused by objective assessment of said health care unit. It needs pointing out that the quality of care, willingness to recommend a medical unit, or desire to return to it are three unique variables, which carry with them certain priorities for the patients which influence patients' satisfaction. ${ }^{46}$

Patient's positive impressions and his/her satisfaction are important sources of information for the hospital. Our study shows that this information helps to identify problems, solve them, and allow the use of such solutions that would aim for quality improvement in the organization's functioning. The same facts are also confirmed in the study by Levine et al. ${ }^{47}$ Also the more engaged the employee, the more satisfied the patient, and thus we can conclude that a health care provider can add quality of patient care to the list of benefits leading to a patient's return to the same hospital if such a need arises along with positive recommendations. The investment in employees has an impact on organization, especially in areas such as internal communication, work culture, and leadership style. ${ }^{48}$ Our study also confirms that an organization which wants to be leader on the health care market must have an adequate number of medical employees (doctors and nurses). Among the strengths of the study were its nationally representative sample and adjustment for potential confounders, such as sociodemographic characteristics, analysis of employee's behavior in surgery wards in public hospitals, and the structure of employment in the surgery ward in Poland. These adjustments were the basis for what was found: higher patient's satisfaction associated with favorable conditions of stay, on which had impact on availability of doctors on the ward, doctor's involvement in explaining the drug therapy, and higher rates of employment in groups of medical employees. The correct proportions of employment of employees are one doctor per 1.5 patients and one nurse per 0.8 patients. Such employment ratios allow employees to be more involved in an individual patient's treatment process and the patient's feel that his/her doctor is fully dedicated to this task. The study shows practical implication for hospital managers. Increasing the number of doctors on a surgery 
ward can improve the engagement of medical employees and their 24/7 availability for patients. Such a situation brings benefits for patients and health organizations alike.

\section{Limitations}

The sample used in this study was restricted to people treated surgically (patients undergoing elective laparoscopic cholecystectomy) with the same International Classification of Diseases-10 code (K80). The structure of employment in a surgery ward in Poland and the engagement of the employees in the treatment process were analyzed. It is true that the number of employees can be different in other hospitals in Poland. Thus, caution should be exercised in generalizing these findings to all hospital wards. However, the authors are not aware of any reason to believe that employee engagement on a surgery ward is different in other hospitals because the number of medical employees are similar in every hospital in Poland. Limitations of the study also include elements associated with patient's view on service quality and his/her subjective feelings. They also include limitations associated with the simplicity of utilized statistics. However, despite all those limitations, there is a potential for the results of this research to be generalized and extended to all the hospitals with surgery wards in Poland because the structure of employment is similar in all hospitals in Poland.

\section{Conclusion}

Organizations that want to improve patient satisfaction and loyalty must pay attention to internal issues related to employee engagement and satisfaction and how they provide care. There is a strong connection between how engaged in the treatment process an employee is and the level of patient's satisfaction. This interpersonal relationship influences not only satisfaction levels but also patients' loyalty and, in the long run, hospital's financial performance. Promotion of medical services by word of mouth recommendations coming from patients is a primary driver in patients' decisions about health care. This research shows that individual employee recognition and collective recognition of hospital employees as a whole were identified as the most important factors in employee engagement in the treatment process and as a factor influencing the high quality of medical care in hospitals. In addition, recognition of employee's behavior and patients' satisfaction are not only viewed as acknowledgment to the medical employees for job satisfaction but also acknowledge the medical employees (doctor/nurses) as being able to participate in the treatment process and being able to listen to patients, which influences patient's loyalty and their willingness to recommend a hospital.
Our study shows practical implication for hospital managers. Increasing the number of doctors on a surgery ward and their 24 hour availability for patients can improve the engagement of medical employees. The quality of medical services will be better assessed by the patients and will increase the willingness to recommend a hospital. We recognize the need to organize training for doctors to talk to the patients and to provide them information during treatment. Despite the larger number of employees in hospitals of group I, this aspect has been assessed by the patient as poor. Such action will help to gain more loyal and satisfied patients and will also benefit the organization.

\section{Acknowledgments}

No funding was provided for this study. The authors would like to thank all contact persons from the participating hospitals in the Kuyavian-Pomeranian region (Poland) for distributing and collecting the questionnaires and also the managers of these hospitals for agreeing to conduct this study in their hospitals.

\section{Disclosure}

The authors report no conflicts of interest in this work.

\section{References}

1. Peltier J, Dahla A. The relationship between employee satisfaction and hospital patient experiences, April 2009 University of WisconsinWhitewater Frank Mulhern Northwestern University. Forum for people performance management and measurement. Available from: http://www.info-now.com/typo3conf/ext/p2wlib/pi1/press2web/html/ userimg/FORUM/Hospital\%20Study\%20-Relationship\%20Btwn\%20 Emp.\%20Satisfaction\%20and\%20Pt.\%20Experiences.pdf. Accessed December 15, 2015

2. Berwick DM. The science of improvement. JAMA. 2008;299(10): 1182-1184

3. Donabedian A. Explorations in Quality Assessment and Monitoring. Ann Arbor, MI: Health Administration Press; 1980.

4. Atkins PM, Marshall BS, Javalgi RG. Happy employees lead to loyal patients. Survey of nurses and patients shows a strong link between employee satisfaction and patient loyalty. J Health Care Mark. 1996; 16(4):14-23.

5. Al-Mailam FF. The effect of nursing care on overall patient satisfaction and its predictive value on return-to-provider behavior: a survey study. Qual Manag Health Care. 2005;14(2):116-120.

6. Richman A. Everyone wants an engaged workforce: how can you create it? Workspan. 2006;49:36-39.

7. Spurgeon P, Clark J, Ham C. Medical leadership: From the Dark Side to Centre Stage. London, UK: Radcliffe Publishing; 2011.

8. Ignatowicz A, Greenfield G, Pappas Y, Car J, Majeed A, Harris M. Achieving provider engagement providers' perceptions of implementing and delivering integrated care. Qual Health Res. 2014;24(12): 1711-1720.

9. Bakker AB, Schaufeli WB. Positive organizational behavior: engaged employees in flourishing organizations. J Org Behav. 2008;29: 147-154.

10. Clark J. Medical engagement: Too Important to be Left to Chance. London, UK: The King's Fund; 2012. Retrieved from: http://www. kings-fund.org.uk/sites/files/kf/medical-engagement-nhs-john-clarkleadership-review2012-paper.pdf 
11. MacLeod D, Clarke N. Leadership and employee engagement: passing fad or a new way of doing business? Int J Leadersh Public Serv. 2010; 6(4):26-30.

12. Saks AM. Antecedents and consequences of employee engagement. J Managerial Psychol. 2006;21:600-619.

13. Shaw K. An engagement strategy process for communicators. Strateg Commun Manage.2005;9(3):26-29.

14. Guthrie M. Engaging physicians in performance improvement. Am J Med Qual. 2005;20(5):235-238.

15. Erlandson E, Ludeman K. Physician engagement and shared accountability: buzzwords, dilemma or choice? Mich Health Hosp. 2003;39(6):28-29. Available from: www.worthethic.com/Updated_Articles/Physician-Engagement_jc_062106.pdf. Accessed March 7, 2012.

16. Taitz JM, Lee TH, Sequist TD. A framework for engaging physicians in quality and safety. BMJ Qual Saf. 2012;21(9):722-728. Available from: http:/qualitysafety.bmj.com/content/early/2011/07/13/ bmjqs-2011-000167.short. Accessed July 20, 2011.

17. Reinertsen JL, Gosfield AG, Rupp W, Whittington JW. Engaging Physicians in a Shared Quality Agenda. IHI Innovation Services white paper. Cambridge, MA: Institute for Healthcare Improvement; 2007. Available from: www.ihi.org/knowledge/Pages/IHIWhitePapers/ EngagingPhysiciansWhitePaper.aspx. Accessed February 27, 2012.

18. Reinertsen JL, Gosfield AG, Rupp W, Whittington JW. Engaging Physicians in a Shared Quality Agenda. IHI Innovation Series white paper. Cambridge, MA: Institute for Healthcare Improvement; 2007. Available from: www.IHI.org. Accessed March 10, 2016.

19. The King's Fund. The Future of Leadership and Management in the NHS: report From The King's Fund Commission on Leadership and Management in the NHS. London, UK: The King's Fund; 2011.

20. Spurgeon P, Barwell F, Mazelan P. Developing a medical engagement scale (MES). Int J Clin Leadersh. 2008;16:213-223.

21. Paraserman A, Zeithaml VA, Berry L. Alternative scales for measuring service quality: a comparative assessment based on psychometric and diagnostic criteria. J Market. 1994;70(3):201-230.

22. Paraserman A, Zeithaml VA, Berry L. Refinement and reassessment of the SERVQUAL scale. J Retail. 1989;64(4):420-450.

23. Paraserman A, Zeithaml VA, Berry L. SERVQUAL: a multiple item scale for measuring customer perceptions of service quality. J Retail. 1988; 64(1):12-40.

24. Paraserman A, Zeithaml VA, Berry L. A conceptual model of service quality and its implications for future research. J Market. 1985;49:8.

25. Rosak J, Borkowski S. Applying of the servqual method to the estimation of the quality of the stationary medical treatment, [w:] Economy and Management of Enterprises in Transition in the Global Market Environment. Pardubice. 2005:49-55.

26. Rao KD, Peters DH, Bandeen-Roche K. Towards patient-centered health services in India - a scale to measure patient perceptions of quality. Int J Qual Health Care. 2006;18(6):414-421.

27. van Duong D, Binns CW, Lcc AH, Hipgrave DB. Measuring clientperceived quality of maternity services in rural Vietnam. Int J Qual Health Care. 2004;16(6):447-452.

28. Mazur J. Marketing Management Services. Warsaw, Poland: Difin Inc; 2002.

29. Lovelock CH, Wright L. Principles of Service Marketing and Management. Upper Saddle River, NJ: Prentice Hall; 1999.
30. Parasuraman A. Measuring and monitoring service quality. In Glynn W, Barnes J, editors. Understanding Services Management. Chichester, UK: Wiley and Sons Publisher; 1995:146-147.

31. Oliver RL. A conceptual model of service quality and service satisfaction: compatible goals, different concepts. In Teresa AS, David EB, Stephen WB, editors. Advances in Marketing and Management. Greenwich, UK: JAI Press; 1993:65-85.

32. Jones MA, Reynolds KE, Arnold MJ. Hedonic and utilitarian shopping value: investigating differential effects on retail outcomes. J Bus Res. 2006;59(9):974-981.

33. Babin BJ, Lee YK, Kim EJ, Griffin M. Modeling consumer satisfaction and word-of-mouth: restaurant patronage in Korea. J Serv Market. 2005;19(3):133-139.

34. Babin BJ, Darden WR, Griffin M. Work and/or fun: measuring hedonic and utilitarian shopping value. J Consum Res. 1994;20(4):644-656.

35. Chitturi R, Raghunathan R, Mahajan V. Delight the role of hedonic versus utilitarian benefits. J Market. 2008;72(3):48-63.

36. Fornell C. A national customer satisfaction barometer: the Swedish experience. J Market. 1992;56(1):6-21.

37. Fornell C, Johnson MD, Anderson EW, Cha J, Bryant BE. The American customer satisfaction index: nature, purpose, and findings. J Market. 1996;60(4):7-18.

38. Ketter P. What's the big deal about employee engagement? Train Dev. 2008;62(1):44 49. Available from: http:/www.findarticles.com/p/articles/ mi_m4467/is_200801/ai_n21302720. Accessed January 30, 2012.

39. Hass JS, Cook EF, Puopolo AL, Burstin HR, Cleary PD, Brennan TA. Is the professional satisfaction of general internists associated with patient satisfaction? J Gen Intern Med. 2000;15(2):122-128.

40. Linn LS, Brook HR, Clark VA, Davies AR, Fink A, Kosecoff J. Physician and patient satisfaction as a factors related to the organization of internal medicine group practices. Med Care. 1985;23(10):1171-1178.

41. MacLeod D, Clarke N. Engaging for Success: enhancing Performance Through Employee Engagement. London: Department for Business, Innovation and Skills (BIS). Available from: http://www. engageforsuccess.org/wp-content/uploads/2012/09/file52215.pdf

42. Utsugi-OzakiM,Bito S, Matsumura S, Havashino Y,Fukuhara S;MEMO-J Study Group. Physician job satisfaction and quality of care among hospital employed physicians in Japan. J Gen Intern Med. 2009;24(3): 387-392.

43. Bruke-Miller JK, Cook IA, Cohen MH, et al. Longitudinal relationship between use of highly active antiretroviral therapy and satisfaction with care among women living with HIV/AIDS. Am J Public Health. 2006; 96(6):1044-1051.

44. Lee KJ. A practical method of predicting client revisit intention in hospital setting. Health Care Manag Rev. 2005;30(2):157-167.

45. Sitzia J, Wood N. Patient satisfaction: a review of issues and concepts. Soc Sci Med. 1997;45(12):1828-1843.

46. Burroughs TE, Davies AR, Cira J, Dunagan WC. Understanding patient willingness to recommend and return: a strategy for prioritizing improvement opportunities. Jt Comm Qual Improve. 1999;25(6):271-287.

47. Levine AS, Plume SK, Nelson EC. Transforming patient feedback into strategic action plans. Qual Manag Health Care. 1997;5(3):28-40.

48. Donald M, Berwick MD. Launching accountable care organizations the proposed rule for the Medicare Shared Savings Program. N Engl J Med. 2011;364(16):e32.
Patient Preference and Adherence

\section{Publish your work in this journal}

Patient Preference and Adherence is an international, peer-reviewed, open access journal that focuses on the growing importance of patient preference and adherence throughout the therapeutic continuum. Patient satisfaction, acceptability, quality of life, compliance, persistence and their role in developing new therapeutic modalities and compounds to optimize

\section{Dovepress}

clinical outcomes for existing disease states are major areas of interest for the journal. This journal has been accepted for indexing on PubMed Central. The manuscript management system is completely online and includes a very quick and fair peer-review system, which is all easy to use. Visit http://www. dovepress.com/testimonials.php to read real quotes from published authors. 